\title{
Down-regulation of miR-181c in imatinib-resistant chronic myeloid leukemia
}

\author{
Neda Mosakhani ${ }^{1}$, Satu Mustjoki ${ }^{2}$ and Sakari Knuutila ${ }^{1 *}$
}

\begin{abstract}
The association of microRNA alterations with progression and treatment outcome has been revealed in different types of cancers. To find miRNAs involved in imatinib response we performed miRNA microarray followed by RT-qPCR verification of 9 available diagnostic bone marrow core biopsies from 9 CML patients including 4 imatinib-resistant and 5 imatinib-responder patients. Only one differentially expressed miRNA, miR-181c, was found when the imatinib-resistant group was compared with imatinib-responders. Significant down-regulation of miR-181C in imatinib-resistant versus imatinib-responders was confirmed by qRT-PCR. Some miR-181c target genes such as PBX3, HSP9OB1, NMT2 and RAD21 have been associated with drug response.
\end{abstract}

Keywords: miRNA, CML, Imatinib response

Chronic myeloid leukemia (CML) is characterized by unregulated proliferation of myeloid cells in the bone marrow that carry the $B C R-A B L$ fusion gene. In most of the patients, the $A B L$ tyrosine kinase of the fusion protein is effectively inhibited by the tyrosine kinase inhibitors (TKIs), but some patients are resistant to TKI therapy. Whereas the $B C R-A B L$ fusion drives the initial chronic phase of the disease, the progression of CML involves additional genomic changes which make leukemia cells resistant to TKI therapy and independent of $B C R-A B L$. Recently, in a variety of cancers the role of microRNAs (miRNA) in disease progression has been addressed [1]. MiRNAs are potential regulators of drug efficacy, because they target many important drug-related genes [2].

To understand which miRNAs are associated with the TKI therapy response, we performed miRNA microarray in 9 bone marrow core biopsies derived from $9 \mathrm{CML}$ patients at diagnosis including 5 imatinib-responder and 4 imatinib-resistant patients. The ABL mutations were not tested at the time of diagnosis, and during the therapy they were only tested for resistant patients. Three of four patients developed mutations later during the treatment, but this occurred 6-10 years after the diagnosis. The study was conducted in accordance with the principles of the

\footnotetext{
*Correspondence: sakari.knuutila@helsinki.fi

'Department of Pathology, Haartman Institute, and HUSLAB, University of Helsinki and Helsinki University Central Hospital, Helsinki, Finland Full list of author information is available at the end of the article
}

Helsinki Declaration and was approved by the Helsinki University Central Hospital Ethics Committee. Written informed consent was obtained from each patient. For clinical information see Table 1.

From core biopsies, total RNA, including miRNA, was isolated with the miRNeasy FFPE Mini Kit (Qiagen, Valencia, CA, USA). To check the quality of total RNA we used the RNA 6000 chip and for miRNA the small RNA chip (Agilent Technologies, Santa Clara, CA, USA) Agilent's Bioanalyzer. An miRNA microarray system (V3) (containing 866 human and 89 human viral miRNAs) (Agilent) was used for miRNA profiling according to Agilent's protocol. Based on our previous study, the core biopsy samples are a reliable source for miRNA profiling [4].

The raw data were analyzed with GeneSpring Software v.11.5.0. The data were preprocessed by taking $\log 2$ and normalized by the 75th percentile method. The T-test was applied to find the most significant differentially expressed miRNAs $(P<0.05$ and False discovery rate or $\mathrm{q}<0.05)$.

Despite the small sample size used in our studywhich indicates the rarity of resistant patients-we found one miRNA, miR-181c, which is differentially expressed between imatinib-resistant and imatinib-responder patients $(P=1.41 \mathrm{E}-6, \mathrm{q}=6.1 \mathrm{E}-4)$. $M i R-181 c$ was validated by quantitative RT-PCR (qRT-PCR) by the use of the SYBR Green miScript PCR system (Qiagen) on the Light-

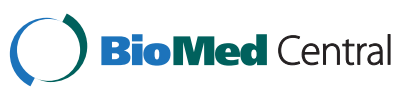


Table 1 Patient characteristics

\begin{tabular}{|c|c|c|c|c|c|c|}
\hline Patient no. & Year of dg & Gender & Age at dg & Sokal score & Treatment & Treatment response \\
\hline 1. & 1996 & $\mathrm{~F}$ & 45 & 7.44 & $\mathrm{HU}, 11 / 96$ IFN, 6/2002 IM, 5/2005 DAS & No CgR \\
\hline 2. & 1998 & $\mathrm{~F}$ & 56 & 1.37 & HU, $3 / 99$ IFN, 04/2002 IM, 08/2006 DAS & Min CgR \\
\hline 3. & 2010 & M & 68 & 1.61 & $\mathrm{HU}, 3 / 2010 \mathrm{IM}, 12 / 2010 \mathrm{NIL}, 6 / 2011 \mathrm{DAS}$ & Min CgR \\
\hline 4. & 2008 & M & 58 & 1.39 & HU, 7/2008 IM, 6/2009 DAS, 3/2010 alloHSCT & No CgR \\
\hline 5. & 2005 & M & 48 & 0.93 & $H U, 11 / 2005$ IM, 2/2006 IM + IFN & CMR \\
\hline 6. & 2005 & M & 58 & 0.77 & $11 / 2005 \mathrm{IM}$ & CMR \\
\hline 7. & 2004 & M & 55 & 0.69 & $H U, 10 / 2004$ IM, 3/2005 IM + IFN & CMR \\
\hline 8. & 2006 & $\mathrm{~F}$ & 53 & 0.68 & $\mathrm{HU}, 1 / 2007 \mathrm{IM}$ & CMR \\
\hline 9. & 2006 & M & 52 & 0.85 & $\mathrm{HU}, 1 / 2007 \mathrm{IM}$ & MMR \\
\hline
\end{tabular}

In all non-responder patients (patients 1-4) the treatment response to imatinib was failure based on the European Leukemia Net (ELN) criteria [3] (no or minimal cytogenetic response to imatinib within 12 months after the start of therapy). These patients were subsequently treated with other TKIs (dasatinib/nilotinib), but no cytogenetic responses were achieved with 2nd generation TKIs either, confirming these patients to be non-responders to multiple TKIs. Patients in the responder group (patients 5-9) fulfilled the optimal response to imatinib based on ELN criteria. Abbreviations: no number, $d g$ diagnosis, $H U$ hydroxyurea, IFN interferon, IM imatinib, DAS dasatinib, NIL nilotinib, alloHSCT allogeneic hematopoietic stem cell transplantation, CgR cytogenetic response, min minimal, CMR complete molecular response, $M M R$ major molecular response.

cycler, software v.3.5 (Roche Applied Science, Mannheim, Germany). The primer sequence for miR-181c was purchased from Qiagen and the primer was 5' AACAUUCAA CCUGUCGGUGAGU. The snRNA U6 gene (Qiagen) served as the normalization control, and relative quantification for each miRNA was calculated using the $2^{-\Delta \Delta C t}$. Significant down-regulation of $\operatorname{miR}-181 c(\mathrm{p}=0.04)$ in imatinib-resistant vs. imatinib-responder patients was confirmed by qRT-PCR (Figure 1 and Additional file 1: Figure S1).

In normal conditions, miR-181c is expressed in the thymus, primary lymphoid organs, brain, lungs, bone marrow, and spleen [5]. MiR-181 has also been associated with the differentiation of both hematopoietic B cells [5] and T cells [6], and myoblasts [7]. MiR-181c is involved in a tumor-suppression pathway [8] and likely in regulation

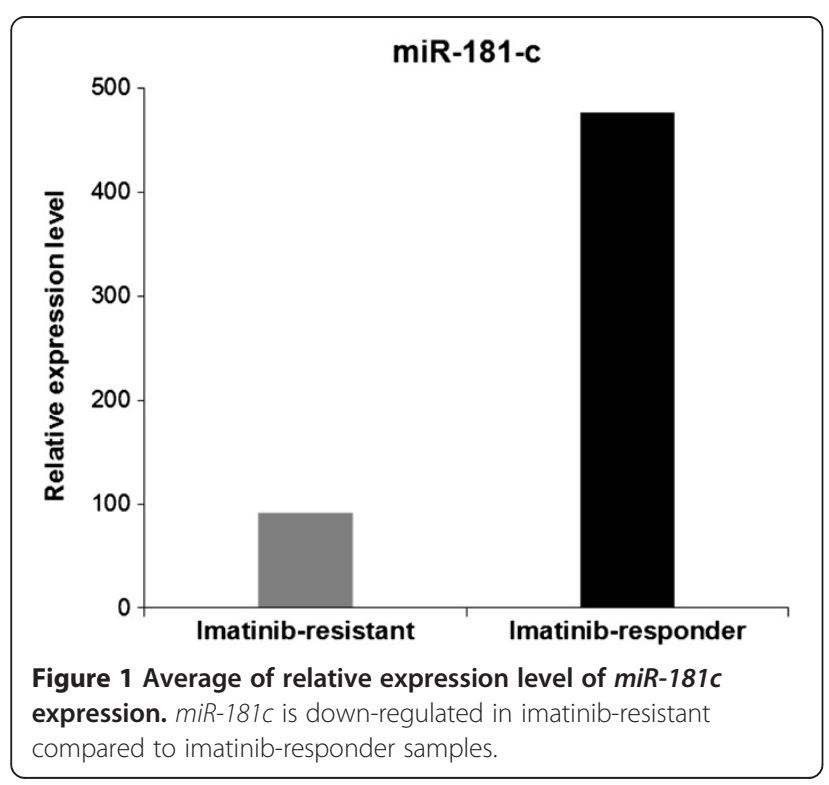

of the $\mathrm{Rb}$ pathway which mediates cell-growth arrest [9]. Its inhibitory effect on cell growth and increasing apoptosis has been observed in glioma cells [8]. In accordance with our finding, the strong down-regulation of the miR181 family, including miR-181c, has been observed in Lynmediated imatinib-resistant CML cells [10]. Similarly, AML patients with intermediate- or poor-risk subtypes have been reported to have lower miR-181 levels than do patients with favorable prognosis [11]. The decreased expression of this miRNA has also been found in Fanconi anemia patients, and been involved in the impaired growth of their hematopoietic progenitors [12]. However, in two recent studies involving CML patients, no association appeared between the miR-181c expression and imatinib therapy response $[13,14]$. Furthermore, in CML patients with blast chrisis, the miR-181c was not differentially expressed, but miR-181a and miR-181b were upregulated [15].

To study which genes are targeted by miR-181c, we used Chipster software v.1.4. To reduce false positivity, target genes needed to be predicted by at least five of six algorithms, including TargetScan, miRanda, Sanger miRBase, mirTarget2, Tarbase, and PICTAR (Additional file 2: Table S1). Some of the miR-181c target genes are associated with prognosis and drug response, ones such as PBX3, HSP90B1, NMT2, and RAD21. For example, AML patients with intermediate- to poor-prognosis subtypes, who had lower expression of miR-181, conversely showed an increased level of $P B X 3$ [16]. The up-regulation of NMT2 and RAD21 contributes to chemoresistance in osteosarcoma cell lines and also in breast cancers $[17,18]$. Similarly, high expression of HSP90B1 is associated in breast cancer with distant metastasis and with decreased overall and disease-free survival [19]. Moreover, high HSP90 expression predicts worse overall survival in patients with acute lymphocytic leukemia [20]. 
In conclusion, $m i R-181 c$ associated with imatinib resistance. Larger sample sizes and further independent studies, however, are warranted to assess the role of candidate miRNA and target genes in the molecular mechanisms underlying resistance in CML.

\section{Additional files}

Additional file 1: Figure S1. Relative expression level of miR-181C in individual samples.

Additional file 2: Table S1. Predicted target genes by at least five databases for miR-181c

\section{Abbreviation}

TKls: tyrosine kinase inhibitors.

\section{Competing interests}

The authors declare that they have no competing interests.

\section{Authors' contributions}

SK, as a senior researcher, designed the study and participated in writing the manuscript. NM performed the laboratory work and participated in writing. SM participated in designing the study and provided clinical data and preparing the manuscript. All authors read and approved the final manuscript.

\section{Acknowledgements}

The study was supported by grants from the Nordic Chronic Myeloid Leukemia Study Group, Juselius, Evo, Finnish Cancer Association. We are grateful to Carolyn Brimley Norris for language revision.

\section{Author details}

'Department of Pathology, Haartman Institute, and HUSLAB, University of Helsinki and Helsinki University Central Hospital, Helsinki, Finland.

${ }^{2}$ Hematology Research Unit Helsinki, Department of Medicine, Division of Hematology, University of Helsinki and Helsinki University Central Hospital, Helsinki, Finland.

Received: 17 April 2013 Accepted: 4 June 2013

Published: 16 July 2013

\section{References}

1. Setoyama T, Ling H, Natsugoe S, Calin GA: Non-coding RNAs for medical practice in oncology. Keio J Med 2011, 60:106-113

2. Rukov JL, Shomron N: MicroRNA pharmacogenomics: Post-transcriptional regulation of drug response. Trends Mol Med 2011, 17:412-423.

3. Baccarani M, Cortes J, Pane F, Niederwieser D, Saglio G, Apperley J, Cervantes F, Deininger M, Gratwohl A, Guilhot F, Hochhaus A, Horowitz M, Horowitz M, Hughes T, Kantarjian H, Larson R, Radich J, Simonsson B, Silver RT, Goldman J, Hehlmann R: Chronic myeloid leukemia: An update of concepts and management recommendations of european LeukemiaNet. J Clin Oncol 2009, 27:6041-6051.

4. Borze I, Guled M, Musse S, Raunio A, Elonen E, Saarinen-Pihkala U, Karjalainen-Lindsberg ML, Lahti L, Knuutila S: MicroRNA microarrays on archive bone marrow core biopsies of leukemias-method validation. Leuk Res 2011, 35:188-195.

5. Chen CZ, Li L, Lodish HF, Bartel DP: MicroRNAs modulate hematopoietic lineage differentiation. Science 2004, 303:83-86.

6. Xue Q, Guo ZY, Li W, Wen WH, Meng YL, Jia LT, Wang J, Yao LB, Jin BQ, Wang T, Yang AG: Human activated CD4(+) T lymphocytes increase IL-2 expression by downregulating microRNA-181c. Mol Immunol 2011, 48:592-599

7. Naguibneva I, Ameyar-Zazoua M, Polesskaya A, Ait-Si-Ali S, Groisman R, Souidi M, Cuvellier S, Harel-Bellan A: The microRNA miR-181 targets the homeobox protein hox-A11 during mammalian myoblast differentiation. Nat Cell Biol 2006, 8:278-84

8. Liu T, Papagiannakopoulos T, Puskar K, Qi S, Santiago F, Clay W, Lao K, Lee Y, Nelson SF, Kornblum HI, Doyle F, Petzold L, Shraiman B, Kosik KS:
Detection of a microRNA signal in an in vivo expression set of mRNAs. PLoS One 2007, 2:e804.

9. Chen A, Luo M, Yuan G, Yu J, Deng T, Zhang L, Zhou Y, Mitchelson K, Cheng J: Complementary analysis of microRNA and mRNA expression during phorbol 12-myristate 13-acetate (TPA)-induced differentiation of HL-60 cells. Biotechnol Lett 2008, 30:2045-2052.

10. Zimmerman El, Dollins CM, Crawford M, Grant S, Nana-Sinkam SP, Richards KL, Hammond SM, Graves LM: Lyn kinase-dependent regulation of miR181 and myeloid cell leukemia-1 expression: Implications for drug resistance in myelogenous leukemia. Mol Pharmacol 2010, 78:811-817.

11. Li Z, Lu J, Sun M, Mi S, Zhang H, Luo RT, Chen P, Wang Y, Yan M, Qian Z, Neilly MB, Jin J, Zhang Y, Bohlander SK, Zhang DE, Larson RA, Le Beau MM Thirman MJ, Golub TR, Rowley JD, Chen J: Distinct microRNA expression profiles in acute myeloid leukemia with common translocations. Proc Natl Acad Sci USA 2008, 105:15535-15540

12. Rio P, Agirre X, Garate L, Banos R, Alvarez L, San Jose-Eneriz E, Badell I, Casado JA, Garin M, Prosper F, Bueren JA: Down-regulated expression of hsa-miR-181c in fanconi anemia patients: Implications in TNFalpha regulation and proliferation of hematopoietic progenitor cells. Blood 2012, 119:3042-3049.

13. San Jose-Eneriz E, Roman-Gomez J, Jimenez-Velasco A, Garate L, Martin V, Cordeu L, Vilas-Zornoza A, Rodriguez-Otero P, Calasanz MJ, Prosper F, Agirre X: MicroRNA expression profiling in imatinib-resistant chronic myeloid leukemia patients without clinically significant ABL1-mutations. Mol Cancer 2009, 8:69.

14. Flamant S, Ritchie W, Guilhot J, Holst J, Bonnet ML, Chomel JC, Guilhot F, Turhan AG, Rasko JE: Micro-RNA response to imatinib mesylate in patients with chronic myeloid leukemia. Haematologica 2010, 95:1325-1333.

15. Machova Polakova K, Lopotova T, Klamova H, Burda P, Trneny M, Stopka T: Expression patterns of microRNAs associated with CML phases and their disease related targets. Mol Cancer 2011, 10:41.

16. Li Z, Huang H, Li Y, Jiang $X$, Chen P, Arnovitz S, Radmacher MD, Maharry K, Elkahloun A, Yang X, He C, He M, Zhang Z, Dohner K, Neilly MB, Price C, Lussier YA, Zhang Y, Larson RA, Le Beau MM, Caligiuri MA, Bullinger L, Valk PJ, Delwel R, Lowenberg B, Liu PP, Marcucci G, Bloomfield CD, Rowley JD, Chen J: Up-regulation of a HOXA-PBX3 homeobox-gene signature following down-regulation of miR-181 is associated with adverse prognosis in patients with cytogenetically abnormal AML. Blood 2012, 119:2314-2324.

17. Walters DK, Steinmann P, Langsam B, Schmutz S, Born W, Fuchs B: Identification of potential chemoresistance genes in osteosarcoma. Anticancer Res 2008, 28:673-679.

18. Xu H, Yan M, Patra J, Natrajan R, Yan Y, Swagemakers S, Tomaszewski JM, Verschoor S, Millar EK, van der Spek P, Reis-Filho JS, Ramsay RG, O'Toole SA McNeil CM, Sutherland RL, McKay MJ, Fox SB: Enhanced RAD21 cohesin expression confers poor prognosis and resistance to chemotherapy in high grade luminal, basal and HER2 breast cancers. Breast Cancer Res 2011, 13:R9.

19. Cawthorn TR, Moreno JC, Dharsee M, Tran-Thanh D, Ackloo S, Zhu PH, Sardana G, Chen J, Kupchak P, Jacks LM, Miller NA, Youngson BJ, lakovlev V, Guidos CJ, Vallis KA, Evans KR, McCready D, Leong WL, Done SJ: Proteomic analyses reveal high expression of decorin and endoplasmin (HSP90B1) are associated with breast cancer metastasis and decreased survival. PLoS One 2012, 7:e30992

20. Hacihanefioglu A, Gonullu E, Mehtap O, Keski H, Yavuz M, Ercin C: Effect of heat shock protein-90 (HSP90) and vascular endothelial growth factor (VEGF) on survival in acute lymphoblastic leukemia: an immunohistochemical study. Med Oncol 2011, 28:846-851.

doi:10.1186/1755-8166-6-27

Cite this article as: Mosakhani et al:: Down-regulation of miR-181c in imatinib-resistant chronic myeloid leukemia. Molecular Cytogenetics 2013 6:27. 